\title{
Should the national diet be altered to prevent coronary disease?
}

\section{By W. P. T. JAmes and ANN RAlPH, Rowett Research Institute, Greenburn Road, Bucksburn, Aberdeen AB2 9SB}

Current recommendations for the prevention of heart disease in Britain appear to be very similar to those of a host of committees around the world. This consistency is sometimes cited as evidence in itself to justify the development of nutritional goals on a public-health basis. Medawar (1985) has noted that when political and administrative problems confront us which turn on scientific evidence then 'scientists should be consulted-and when their advice is concordant, it should be acted on'. Medawar (1985) neglects the problem of what constitutes concordance and the importance of other non-scientific factors such as economic, social and political issues in governmental decision making. He does, however, recognize that in some debates, e.g. on the fluoridation of public water supplies, there is the problem of 'convincing the disaffected minorities'. The question is therefore whether in developing a dietary policy on heart disease we are dealing with a 'disaffected minority' within the scientific community or within the public domain. It seems clear that we have a few genuine critics among the scientific community who do not consider that there is a need to develop a national food policy for the prevention of coronary heart disease. They might well echo the words of Richard Asher (1972): 'Please do not write any more articles about cholesterol and coronary disease and the diet and drugs which are supposed to influence them. The facts about coronary disease are these: the less atheromatous your ancestors, the harder your water and the more habitual exercise you take, the less likely you are to be troubled by it. Do stop bothering about whether your fats are saturated or unsaturated, help yourself liberally to butter and stop propagating these erroneous legends.'

Harper (1983) considers the proposition that we are suffering from a modern epidemic of heart disease as reflecting muddled thinking and the changing classifications of cardiovascular disease. Mitchell (1984), however, regards the epidemiological evidence on the benefits of dietary change as inconsistent, scientifically imprecise and overshadowed by wishful thinking. Perhaps, then, the reason why a new committee comes to the same assessment as the old expert committees around the world simply reflects the embarrassment as well as the difficulty in justifying a new approach to dietary policy when so many previous expert groups seem able to agree.

\section{The development of public health policies in Britain}

In the heyday of British nutrition, during the three decades from about 1930, nutritionists and doctors felt happy encompassing their very different fields of endeavour, i.e. scientific research, public policy-making and finally nutrition and health education. The different operational bases for each activity were well understood. After the Second World War, however, there was a progressive decline in nutritional research in Britain, accompanied by a withdrawal from policy-making and from involvement in health education. Forty years ago there was little evidence of the recrimination, personal vindictiveness and intrigue which is considered characteristic of the British nutrition scene in the 1980s. Perhaps what we are witnessing today is the slow process of relearning the need to engage in policy-making and public education as well as research. The distinctions and relations between these three fields still, however, seem to remain obscure to many nutritionists. 
The previous food policies were developed in an atmosphere of controversy, as Boyd Orr (1966) well described. Yet public health policy-making had had many successes. As Medawar (1985) records, Edwin Chadwick's 1842 report on sanitary conditions of the labouring population of Great Britain led to the Public Health Act of 1844. These proposals placed costly obligations on public funds and manufacturers, and the Act aroused much public displeasure. Indeed, the proposal to lay a main sewer in London led The Times to comment 'We prefer to take our chance of cholera and the rest than be bullied into health'. Prince Albert's untimely death from cholera at the age of 42 , as the cesspools of Windsor castle overflowed, was a sad reminder of The Times' inability to protect its own. Its current opinion on public health policy, this time in relation to food, is little different in tone.

McKeown (1976) considers that the hygienic measures introduced progressively from the second-half of the nineteenth century were second only to nutrition in their contribution to health, and Cochrane (1972) has reminded us that medical advances played little part in accounting for the improved health of the nation and were certainly not preceded by any formal community tests to establish the value of the proposed reforms.

During the Second World War, Lord Woolton has described (Rowett Research Institute, 1955) how he was 'charged with the task of feeding a nation largely dependent on overseas supplies of food. . . . Faced with this threat to our survival I decided to try to develop a food policy based on our scientific knowledge of those engaged in the study of nutrition and biochemistry, translated in terms of a diet restricted by war-time conditions of supply'. He relied on Boyd Orr's work and that of others noting that 'something of the correlation between health and diet was beginning to be understood. Milk as a food for growing children came into its own and the school-meal service completed the task of establishing in the young the foundation of a stamina that would lead to a healthy maturity'. Boyd Orr (Rowett Research Institute, 1955) noted that in 1926-7 an experiment with 1500 children done by the Rowett Institute showed that the addition of milk made a definite improvement in rate of growth and health in ordinary children not suffering from any obvious disease.' Overproduction of milk and inadequate milk consumption by children was acknowledged by Mr Stanley Baldwin, the then Prime Minister, who considered the two problems should be made to cancel each other out. ' $\mathrm{By}$ providing cheap or free milk to mothers and children and raising the allowance for the children of the unemployed, steps were taken to bring a diet adequate in health within the purchasing power of the poorest families'. Boyd Orr also records (Rowett Research Institute, 1955) how a 'nutrition campaign' to get a diet adequate for health within the reach of the poorest was carried out by many leading scientists, including Sir Frederick Gowland Hopkins. Evidently in those days it was respectable for renowned Oxbridge biochemists to engage in nutrition campaigns.

By 1942 all wheat flour except wholemeal was fortified with calcium carbonate; thiamin was added to white flour from 1940 to 1942 . The Ca fortification programme was introduced in part from what appeared to be strong evidence that the absorption of $\mathrm{Ca}$ was affected by "toxamins" present in certain foods'. The subsequent change in food law based on expert scientific committee reviews have all been well summarized in the report on bread by the Committee on Medical Aspects of Food Policy (COMA) (Department of Health and Social Security (DHSS), 1981). If one examines the basis for the changes in policy it is clear that none of the evidence remotely matches the wealth of information currently available on dietary aspects of heart disease.

In the early 1940s, Ca was added to wheat flour because bread was eaten by a majority of the population and other sources, such as milk and cheese, were likely to be scarce. 
The war-time high extraction rate with increased phytate in the bread hindered Ca absorption. In 1953 the control of extraction ceased but the illogical step was taken to add $\mathrm{Ca}$ to all flour except wholemeal flour. In 1960, in spite of uncertainty regarding signs of $\mathrm{Ca}$ deficiency and any problems of rickets and osteomalacia, vitamin $\mathrm{D}$ was reduced in some welfare foods to avoid the problem of infantile hypercalcaemia but $\mathrm{Ca}$ was still added to flour. In 1974, after deciding that the $\mathrm{Ca}$ intake of the population was approximately double the DHSS (1969) recommended intake level, it was decided to continue with the addition because of the possible link of cardiovascular disease with soft-water areas. Yet there is little sound evidence that $\mathrm{Ca}$ in domestic water is a protective factor against heart attacks. By 1981 the DHSS decided that there was no justification in adding $\mathrm{Ca}$ to flour.

The policy-making in relation to iron was also based on flimsy evidence. Since $1953 \mathrm{Fe}$ has been added to all flour of less than $100 \%$ extraction simply to restore the natural level of $\mathrm{Fe}$ in flour which had seemed to provide for health during the war. Several absorption studies, however, showed that the forms of Fe used are poorly absorbed. The DHSS (1981) noted little evidence of widespread Fe deficiency except in special conditions which could be treated separately, so they found no advantage in the continued adding of Fe to flour. Yet about $\mathbf{3 0 \%}$ of British women have no Fe stores as judged by their low serum ferritin concentrations and in other countries this is considered a reason for Fe supplementation.

The addition of thiamin to flour dates from a time when bread formed a greater part of the diet than at present and the loss of thiamin during milling gave cause for concern. However, with thiamin deficiency seemingly of little clinical importance the continued addition of thiamin to flour is considered unnecessary. The same was concluded for nicotinic acid and other vitamins and trace elements.

These are all examples of how policy is regularly developed on the basis of incomplete or indeed conflicting scientific evidence. These limitations are not cited to support the introduction of dietary policies on the basis of incomplete evidence which eventually proves to be wrong, but to highlight the readiness with which nutritionists have engaged in policy-making when the problem seems to be important.

While nutritionists have been struggling to relearn their proper role in formulating national strategies for improving public health, the medical profession has fared little better. The majority of doctors are not tuned to thinking in terms of community health. Although some are trained to think scientifically, e.g. testing an hypothesis experimentally, most doctors emphasize the clinical analysis of individual patients with all their complex needs. This approach often ignores the paucity of information on effective therapies for the patient's condition. Thus there is a vast outlay of money on drugs which have never been shown on a systematic cost-benefit analysis to be appropriate. Indeed it is curious how many professors of medicine and other senior medical academics in Britain find it outrageous that one should advocate reducing sodium intake in a population or even in patients with moderate degrees of hypertension. Yet these doctors are quite happy to continue with chronic drug therapy known to have a variety of untoward effects which are potentially more disadvantageous than the hypertension itself (Kuller et al. 1986). In other words, the British medical profession is still tuned to anecdotal and individualized therapy without regard to the need for rigorous therapeutic trials before they begin treating their patients. This also applies to the general practitioner's work, so we can safely assume that $75 \%$ of the population who visit a doctor's surgery each year are subject to 'clinical judgement' which includes hunches and unsupported theory. This is the normal approach to medical management in Britain so it is surprising that members of the medical profession should be so savage in their analysis 
and rebuttal of policy proposals. Perhaps they find it simpler to be critical of policy-making outside their own sphere of interest. Given such a background of nutritional and medical thinking it is even more remarkable that the Royal College of Physicians and the British Medical Association have felt able to advocate change in public health policy on diet and heart disease. This unusual step owes much to the small group of epidemiologists and community physicians who are able to think about the problem of health in a population.

\section{Diet and heart disease}

One of the major contributions of the recent COMA report on diet and cardiovascular disease (DHSS, 1984) was in explaining to physicians, medical scientists, nutritionists and the representatives of those sectors of the food industry who felt threatened by the report that all the experts contributing to the panel agreed that the evidence for the recommendations fell short of proof. Nine of the panel of ten agreed that a decreased dietary intake of saturated fatty acids and total fat was desirable to reduce the incidence of coronary artery disease. The tenth member believed that benefit may accrue in so far as the recommended change in diet contributes to the avoidance of obesity. These statements and the use of other phrases highlighting the complex and uncertain nature of the task of policy-making were to me self-evident but the surprise and relief with which these statements were received was proof of the appropriateness of their use. The careful choice of conditional phrases in effect helped to educate the nutritional and medical community about the nature of policy-making. Individual scientists who have little or no experience of policy-making were reassured that their own idiosyncratic views on the causes of heart diseases could be maintained and welcomed the change in tone from that of the NACNE report (National Advisory Committee on Nutrition Education, 1983) which they had wrongly construed as a policy rather than a health education document.

The evidence for the dietary recommendations is given in very flimsy form in the COMA report (DHSS, 1984) but other reviews are cited in the report (e.g. American Heart Association Nutrition Committee (AHANC), 1982) and evidence can be found in AHANC (1982) and elsewhere (Olsen, 1979; Lewis et al. 1986). Interestingly, many nutritionists and scientists are happy to advocate dietary measures, e.g. a low-fat diet for the avoidance of obesity, when there is far less evidence for preventing obesity with a low-fat diet than preventing coronary heart disease with a low-saturated-fatty-acid intake. Whilst a low-fat diet has been advocated by the Royal College of Physicians Working Party on Obesity (Royal College of Physicians, 1983) this recommendation stems from very limited evidence indeed: there are no fully published clinical trials, let alone epidemiological studies or population intervention studies which can be cited to justify such a policy. Furthermore, obesity as such is not an independent contributor to coronary heart disease unless one wishes to exaggerate the minute effect (independent of the risk factors of blood pressure and serum cholesterol) which becomes apparent in very-long-term studies. The contrast in scientific rigour demanded to prove the effectiveness of dietary change for the prevention of obesity and coronary heart disease is startling.

On a scientific basis I consider the lipid hypothesis to be incomplete and many epidemiological inconsistencies can be identified (W. P. T. James and K. W. J. Wahle, unpublished results). It takes no great intellectual feat to find objections to the theory that saturated fatty acids as a class of compounds are particularly conducive to the development of heart disease through their effects on increasing serum cholesterol concentrations. For example, it is still not clear which saturated fatty acids are particularly effective in increasing serum cholesterol, nor is it known what the 
mechanism is for the induction of atherosclerosis when hypercholesterolaemia occurs. The theories of Duguid (1954) and Ross (1986) suggesting that either platelet thrombi or endothelial sloughing is the key to atherosclerosis have been replaced by a current theory dependent on the proliferation of mast cells and their stimulation of smooth muscular proliferation and fibrosis (Wosu et al. 1984). These mechanistic uncertainties would make many a biochemist unhappy. Without a clear-cut mechanism one is far less sure that one can rely on the mix of studies-in vitro, animal, human metabolic, clinical, epidemiological and intervention-all of which have been cited as being involved in developing the theory that a high blood cholesterol concentration increases the risk of atherosclerosis and coronary artery disease.

Despite all these difficulties the most recent analyses of the results of the intervention trials in those at high risk of heart disease (Hjermann et al. 1981; AHANC, 1982; Lipid Research Clinics Program, 1984; Cutler et al. 1985; Lewis et al. 1986; Marmot, 1986) and those of the World Health Organization European Collaborative Group (1986) European trial on factory workers are, in my view and that of others, sufficiently telling to justify the policy advocated by COMA (DHSS, 1984) as an intermediate and pragmatic step towards the dietary goals advocated by the World Health Organization (1982). I am sure these policies will change as our mechanistic understanding of the pathogenesis of coronary artery disease improves. Nevertheless I consider that the current policy will eventually prove to be less inconsistent than the nutritional policy on, for example, the fortification of bread. One can only hope that, with the changes in food habits in Britain which have occurred within the last 3-4 years (Lean Cuisine, 1986), we will soon see a decline in morbidity and mortality from coronary heart disease. If not, the critics can maintain their credibility until their advice is requested: they will then have to choose between maintaining the 'no policy option', with its acceptance of some responsibility for Britain continuing to be at the top of the world league for heart disease, and refining or changing policy on the basis of a careful judgement about the benefits and risks of dietary change. The argument that we in the scientific community will lose credibility by being proven wrong seems to be a powerful one with some academics. Those who hold this view are perhaps best left in their ivory towers so that when the fall in coronary heart disease does occur they can still sustain their critical stance, by disputing the basis for the observed change.

\section{REFERENCES}

American Heart Association Nutrition Committee (1982). Arteriosclerosis 4, 177-191.

Asher, R. (1972). Talking Sense. London: Pitman Medical.

Boyd Orr, J. (1966). As I Recall. London: MacGibbon and Kee.

Cochrane, A. L. (1972). Effectiveness and Efficiency: Random Reflections on Health Services. London: The Nuffield Provincial Hospitals Trust.

Cutler, J. A., Neaton, J. D., Hulley, S. B., Kuller, L., Oglesby, P. \& Stamler, J. (1985). Preventive Medicine $14,293-311$.

Department of Health and Social Security (1969). Recommended Intakes of Nutrients for the United Kingdom. Report on Public Health and Medical Subjects no. 120. London: H.M. Stationery Office.

Department of Health and Social Security (1981). Committee on Medical Aspects of Food Policy Report no. 23. London: H.M. Stationery Office.

Department of Health and Social Security (1984). Diet and Cardiovascular Disease. Committee on Medical Aspects of Food Policy Report no. 28. London: H.M. Stationery Office.

Duguid, J. B. (1954). Lancet i, 891-895.

Harper, A. E. (1983). American Journal of Clinical Nutrition 37, 669-681.

Hjermann, I., Byre, K. V., Holme, L. \& Leren, P. (1981). Lancet ii, 1303-1310.

Kuller, L. H., Hulley, S. B., Cohen, J. D. \& Neaton, J. (1986). Circulation 73, 114-123. 
Lean Cuisine (1986). The Lean Lifestyle Report. Findus.

Lewis, B., Mann, J. I. \& Mancini, M. (1986). Lancet i, 956-959.

Lipid Research Clinics Program (1984). Journal of the American Medical Association 251, 351-364.

McKeown, T. (1976). The Role of Medicine: Dream, Mirage or Nemesis. London: The Nuffield Provincial Hospitals Trust.

Marmot, M. G. (1986). Lancet i, 897-900.

Medawar, P. (1985). The Limits of Science. Oxford: Oxford University Press.

Mitchell, J. R. A. (1984). International Journal of Cardiology 5, 287-298.

National Advisory Committee on Nutrition Education (1983). Proposals for Nutritional Guidelines for Health Education in Britain. London: Health Education Council.

Olsen, R. (1979). In Nutrition, Lipids and Coronary Heart Disease: A Global View, pp. 349-364 [R. I. Levy, B. M. Rifkind, B. H. Dennis and N. D. Ernst, editors]. New York: Raven Press.

Ross, R. (1986). New England Journal of Medicine 314, 488-500.

Rowett Research Institute (1955). Rowett Research Institute Report to the Carnegie United Kingdom Trust. Dunfermline: Carnegie United Kingdom Trust.

Royal College of Physicians (1983). Journal of the Royal College of Physicians 17, 3-58.

World Health Organization (1982). Prevention of Coronary Heart Disease. Technical Report Series no. 678. Geneva: WHO.

World Health Organization European Collaborative Group (1986). Lancet i, 869-875.

Wosu, L., McCormick, S. \& Kalart, N. (1984). Canadian Journal of Biochemistry and Cell Biology 62, 984-990. 